\title{
Conjugate Electrospinning Construction of Microyarns with Synchronous Color-Tuned Photoluminescence and Tunable Electrical Conductivity
}

\author{
LIBING FAN, ${ }^{1}$ QIANLI MA, ${ }^{1,2}$ JIAO TIAN,${ }^{1}$ DAN LI,${ }^{1}$ XUE XI,${ }^{1}$ \\ XIANGTING DONG (1D), ${ }^{1,3}$ WENSHENG YU, ${ }^{1}$ JINXIAN WANG, ${ }^{1}$ \\ and GUIXIA LIU ${ }^{1}$ \\ 1.-Key Laboratory of Applied Chemistry and Nanotechnology at Universities of Jilin Province, \\ Changchun University of Science and Technology, Changchun 130022, China. 2.-e-mail: \\ maqianlimail@163.com.3.-e-mail: dongxiangting888@163.com
}

\begin{abstract}
Here, we report a strategy for constructing $\left\{\left[\mathrm{Tb}(\mathrm{BA})_{3}\right.\right.$ phen $+\mathrm{Eu}(\mathrm{BA})_{3}$ phen $] /$ $\mathrm{PAN}\} / / \mathrm{PANI} / \mathrm{PAN}] \quad(\mathrm{BA}=$ benzoic $\quad$ acid, $\quad$ phen $=$ phenanthroline, PANI = polyaniline, $\mathrm{PAN}=$ polyacrylonitrile) hetero-structured microyarns simultaneously endowed with the bi-functionality of tunable luminescence colors and electrical conductivity by using a conjugate electrospinning technique. The obtained hetero-structured microyarns are composed of $\left[\mathrm{Tb}(\mathrm{BA})_{3}\right.$ phen $+\mathrm{Eu}(\mathrm{BA})_{3}$ phen]/PAN luminescent nanofibers and PANI/PAN electrically conductive nanofibers, realizing efficient separation of dark-colored PANI from rare earth (RE) complexes, and thus the enhanced luminescent performance is obtained. Under 276-nm ultraviolet light excitation, the emitting light color of the hetero-structured microyarns can be adjusted in a broad range of green-yellow-red by changing the proportion of RE complexes. The electrical conductivity of the hetero-structured microyarns also can be modulated via tuning the percentages of PANI. These hetero-structured microyarns, by virtue of their luminescent properties and electrical performance, are expected to be applied in multifunctional applications.
\end{abstract}

Key words: Microyarn, conjugate electrospinning, photoluminescence, electrical properties

\section{INTRODUCTION}

With the rapid development of modern science and technology, the requirements for developing nano/micro materials are on the increase. ${ }^{1-22}$ Since the monofunctional nanomaterials cannot satisfy the complex demands of actual applications, researchers have devoted increasing attention to materials composed of two or more kinds of components with desirable performances that are highly integrated into one material. Such multifunctional nanomaterials exhibit obvious advantages. ${ }^{23,24}$ Among the kinds of multifunctional nanomaterials,

(Received February 21, 2018; accepted December 29, 2018; published online January 8, 2019) those with adjustable fluorescent color-electricity bifunctionality are possible candidates in the fields of color display, biomedicine and electronics. ${ }^{25,26}$ For example, Lun and co-workers prepared $\left[\mathrm{Tb}(\mathrm{BA})_{3}\right.$ phen $+\mathrm{Eu}(\mathrm{BA})_{3}$ phen $] /$ polyaniline(PANI)/ polyvinylpyrrolidone(PVP) nanofibers via a simple electrospinning method. ${ }^{26}$ Rare earth (RE) complexes, as luminescent materials, have excellent properties including multicolor emission through doping different $\mathrm{RE}$ ions, high efficiency downconversion luminescence and high photostability, which display unique multifunctional features and potential applications. ${ }^{27-30}$ Conductive polymers like PANI, polypyrrole ( $\mathrm{PPy}$ ), polyacetylene (PA), and polythiophene have many desirable characteristics such as good mechanical properties, excellent environmental stability and tunable 
conductivity. ${ }^{31,32}$ PANI, in particular, with low cost, easy preparation and high pseudocapacitance has become a popular material for applications in chemical sensor, supercapacitors, antistatic coatings, etc. ${ }^{33-36}$ As we know, the luminescent property of $\mathrm{RE}$ complexes will greatly decrease if PANI is directly mixed with them; therefore, we must avoid their direct contact if we wish to obtain multifunctional nanomaterials with strong fluorescence properties. Thus, we urgently need to find new methods to achieve effective separation of the two substances.

Over the past a few years, electrospinning has gained more and more attention as one of the most effective and applicable methods for fabricating functional nanofibers for potential use in optical devices, filtration, tissue engineering, sensors and biomaterials. ${ }^{37-43}$ Electrospun nanofibers are always fascinating, based on their unique properties such as large surface areas, high tensile strength, porosity and the ability to be endowed with multiple functions. ${ }^{44-46}$ However, most of the current electrospun nanofibers are collected in the shape of conventional non-woven membranes with relatively disordered structure and weak mechanical properties, which has limited the applications of nanofibers. ${ }^{47-50}$ Recently, many researchers have shifted their attention from unordered nanofiber membranes to oriented nanofiber bundles or yarns in order to overcome this obstacle and open up new application areas for nanofibers. ${ }^{51-53}$ Several efforts have been reported for fabricating nanofiber yarns with highly aligned structure, unique performance and new applications. Fahimeh and co-workers prepared nanostructured polyacrylonitrile (PAN) yarns by using liquid crystal graphene oxide and PAN. The research provides a new technique for the fabrication of continuously, strongly, and uniformly twisted nanofiber yarns. ${ }^{54}$ Fan and co-workers fabricated heterogeneous nanofiber yarns with well-organized structure and excellent bifunctionality of fluorescence and magnetism by using a conjugate electrospinning technique. ${ }^{55} \mathrm{Li}$ and coworkers reported a dual spinneret system to prepare uniform poly(L-lactic acid) (PLLA) nanofiber yarn which was constructed of uniaxially aligned nanofibers. ${ }^{56} \mathrm{Wu}$ and co-workers manufactured uniaxially aligned coaxial nanofiber yarn (UACNY) consisting of PANI/PAN core-shell structured nanofibers by combining a new electrospinning technique with an in situ solution polymerization process; the resulting UACNY exhibited stable structure, excellent mechanical performance and high gas sensing properties, and will likely have potential applications in wearable smart textiles. ${ }^{57}$

PAN has been widely applied in preparing electrospun nanofibers, which show merits like spinnability, commercial availability, etc. ${ }^{58-61}$ Herein, we designed and assembled tunable luminescent color-electricity bi-functionality into one single new-typed $\left\{\left[\mathrm{Tb}(\mathrm{BA})_{3}\right.\right.$ phen $+\mathrm{Eu}(\mathrm{BA})_{3}$ phen $] /$
PAN\}//PANI/PAN] nanofiber yarn using a cconjugate electrospinning methodology. $\left\{\left[\mathrm{Tb}(\mathrm{BA})_{3}\right.\right.$ phen + $\mathrm{Eu}(\mathrm{BA})_{3}$ phen $\left.] / \mathrm{PAN}\right\} / /[\mathrm{PANI} / \mathrm{PAN}]$ nanofiber yarn consists of two different types of nanofibers, that is, $\left[\mathrm{Tb}(\mathrm{BA})_{3}\right.$ phen $+\mathrm{Eu}(\mathrm{BA})_{3}$ phen $] / \mathrm{PAN}$ color-tuned luminescent nanofibers and PANI/PAN electrical nanofibers, and so is termed a hetero-structured microyarn. The rational design conception enables efficient separation of conductive substances (PANI) from RE complexes, achieving enhanced luminescence and electrical performance, which might pave the way for future applications. To manifest the unique properties of hetero-structured microyarn, $\left\{\left[\mathrm{Tb}(\mathrm{BA})_{3}\right.\right.$ phen $+\mathrm{Eu}(\mathrm{BA})_{3}$ phen $\left.] / \mathrm{PANI} / \mathrm{PAN}\right\}$ microyarn, which is denoted as homo-structured microyarn, was also fabricated by the same method. The homo-structured microyarn is composed of only one kind of nanofiber, namely $\left[\mathrm{Tb}(\mathrm{BA})_{3}\right.$ phen $+\mathrm{Eu}(\mathrm{BA})_{3}$ phen]/PANI/PAN nanofibers. Subsequently, the samples were measured by using a series of modern characterizations, and some new interesting results were gained. As far as we know, there is no literature on manufacturing microyarns with luminescent color-electricity bi-functionality. Moreover, the new hetero-structured microyarns have possible applications in full-color displays, sensor, drug targeting and imaging.

\section{EXPERIMENTAL SECTION}

\section{Materials}

$N, N$-Dimethylformamide (DMF), Polyacrylonitrile (PAN, $\mathrm{Mw} \approx 86000$ ), concentrated nitric acid $\left(\mathrm{HNO}_{3}\right)$, benzoic acid (BA), aniline (ANI), ammonia $\left(\mathrm{NH}_{3} \cdot \mathrm{H}_{2} \mathrm{O}\right), 1,10$-phenanthrolin (phen), ammonium persulfate (APS) and (1S)-(+)-camphor-10 sulfonic acid (CSA) were analytically pure. Both the purity of $\mathrm{Tb}_{4} \mathrm{O}_{7}$ and $\mathrm{Eu}_{2} \mathrm{O}_{3}$ were $99.99 \%$. All the reagents used in the experiments were purchased from Aladdin Chemistry Co., Ltd.

\section{Syntheses of Terbium and Europium Complexes}

In this study, we used the traditional method described in our previous work to prepare terbium and europium complexes. ${ }^{62,63}$

\section{Preparation \\ of $\left\{\left[\mathrm{Tb}(\mathrm{BA})_{3}\right.\right.$ phen $+\operatorname{Eu}(\mathrm{BA})_{3}$ phen $\left.] / \mathrm{PAN}\right\} / /$ \\ [PANI/PAN] Luminescent-Electrical Bi-functional Hetero-Structured Microyarns via Conjugate Electrospinning}

In luminescent-electrical bi-functional heterostructured microyarns, $\mathrm{Tb}(\mathrm{BA})_{3}$ phen and $\mathrm{Eu}(\mathrm{BA})_{3}$ phen complexes act as luminescent materials, PANI is used as electrically conductive substance, and PAN serves as the skeleton of the microyarns.

Appropriate amounts of $\mathrm{Tb}(\mathrm{BA})_{3}$ phen, $\mathrm{Eu}(\mathrm{BA})_{3}$ phen and PAN were dissolved into DMF, mechanically stirring to form a homogeneous 
stable spinning solution A for the preparation of luminescent nanofibers. PAN, DMF, CSA and ANI were added into a conical flask with mechanical stirring $\left(80^{\circ} \mathrm{C}\right)$ for $3 \mathrm{~h}$ to generate a mixture solution. Oxidant APS and solvent DMF were mixed uniformly in another glass bottle. Both of the solutions were kept at $0^{\circ} \mathrm{C}$ for $1 \mathrm{~h}$, and were then mixed together. After that, the mixture was mechanically stirred in an ice-water bath for $2 \mathrm{~h}$. Subsequently, the reaction system was kept at $0^{\circ} \mathrm{C}$ for $24 \mathrm{~h}$ to form spinning solution $\mathrm{B}$ for the fabrication of electrically conductive nanofibers. The amounts of materials in spinning solution A and B are listed in Tables I and II, respectively. The hetero-structured microyarns prepared by $\mathrm{S}_{\mathrm{A} 1} / /$ $\mathrm{S}_{\mathrm{B} 2}, \mathrm{~S}_{\mathrm{A} 2} / / \mathrm{S}_{\mathrm{B} 2}, \mathrm{~S}_{\mathrm{A} 3} / / \mathrm{S}_{\mathrm{B} 2}, \mathrm{~S}_{\mathrm{A} 4} / / \mathrm{S}_{\mathrm{B} 2}, \mathrm{~S}_{\mathrm{A} 5} / / \mathrm{S}_{\mathrm{B} 2}, \mathrm{~S}_{\mathrm{A} 6} / / \mathrm{S}_{\mathrm{B} 2}$, $\mathrm{S}_{\mathrm{A} 7} / / \mathrm{S}_{\mathrm{B} 2}, \mathrm{~S}_{\mathrm{A} 4} / / \mathrm{S}_{\mathrm{B} 1}, \mathrm{~S}_{\mathrm{A} 4} / / \mathrm{S}_{\mathrm{B} 3}$ and $\mathrm{S}_{\mathrm{A} 4} / / \mathrm{S}_{\mathrm{B} 4}$ are defined as $\mathrm{S} 1-\mathrm{S} 10$.

In this work, we used a conjugate electrospinning technique to prepare hetero-structured microyarns. Figure 1 schematically illustrates the formation process of hetero-structured microyarns. The process involves three parts: (1) Solution A and solution $\mathrm{B}$ were respectively drawn into two plastic syringes connected to the negative and positive power supplies. Then the syringes were fixed on the left and right sides of the funnel and the metal wire was placed under the funnel. The charged jets were ejected after the power supplies were connected. Then the ordered nanofibers were generated between the edges of funnel and metal wire, as depicted in Fig. 1a. (2) Hollow-cone shaped nanofiber bundles were formed via revolving the funnel, and the twisted microyarn was simultaneously obtained between the nanofiber bundles and the endpoint of the metal wire, as seen in Fig. 1b. (3) The length of the microyarn become longer by slowly moving down the wire. After the length of the microyarn was enough, the microyarn was wrapped around the metal rod to achieve continuous and automatic collection, as displayed in Fig. 1c. The PAN-based microyarns were obtained at room temperature, $30 \pm 5 \%$ of relative humidity and $100 \mathrm{r} \mathrm{min}^{-1}$ of funnel rotating speed.

To study the influence of twisting degree on the electrical properties of the microyarns, a series of hetero-structured microyarns were prepared by using solutions A4 and B2 under various revolving velocities of the funnel. The rotational speeds of funnel were $10 \mathrm{r} \mathrm{min}{ }^{-1}, 40 \mathrm{r} \mathrm{min}^{-1}, 70 \mathrm{r} \mathrm{min}^{-1}$ and $100 \mathrm{r} \mathrm{min}{ }^{-1}$, and the corresponding samples were expressed as S11, S12, S13 and S4, respectively.

\section{Preparation}

of $\left\{\left[\mathrm{Tb}(\mathrm{BA})_{3}\right.\right.$ phen $+\operatorname{Eu}(\mathrm{BA})_{3}$ phen $\left.] / \mathrm{PANI} / \mathrm{PAN}\right\}$

Luminescent-Electrical Bi-functional

Homo-Structured Microyarns via Conjugate

Electrospinning

To demonstrate the superiority of the heterostructured microyarns, luminescent-electrical bifunctional homo-structured microyarns were also prepared as a contrast sample, which was named as S14. The fabrication of S14 was similar to that of hetero-structured microyarns (S4) except for the spinning solution. Spinning solution for fabricating S14 was produced as follows: solutions A4 and B2 were blended together in a conical flask under mechanical stirring for $2-3 \mathrm{~h}$; the volume ratio of the solution A4 to solution B2 was set as 1:1. Then, conjugate electrospinning was carried out until the spinning solutions were simultaneously and completely consumed.

\section{Characterization}

The morphology of the microyarns was characterized by scanning electron microscope (SEM, XL30). The composition of the microyarns was analyzed via energy-dispersive $\mathrm{x}$-ray spectroscopy (EDS), which was attached to the SEM equipment. The conductivity of the samples was detected by using a four-probe tester (RTS-4). A fluorescence spectrophotometer F-4500 was used to analyze the luminescent performance of microyarns.

\section{RESULTS AND DISCUSSION}

\section{Morphology and Structure}

The morphology and structural characteristics of the hetero-structured and homo-structured microyarns were investigated by SEM with different magnifications. As shown in Fig. 2a and e, it is obviously observed with low magnification of SEM that the rope-shaped samples have clearly twisted

Table I. Compositions of spinning solution A

\begin{tabular}{|c|c|c|c|c|c|}
\hline Solution A & $\begin{array}{l}\text { Mass ratios of } \operatorname{Tb}(\mathrm{BA})_{3} \text { phen } \\
\text { to } \operatorname{Eu}(\mathrm{BA})_{3} \text { phen }\end{array}$ & $\operatorname{Tb}(\mathbf{B A})_{3}$ phen $(\mathrm{g})$ & $\operatorname{Eu}(\mathbf{B A})_{3}$ phen $(\mathrm{g})$ & DMF (g) & PAN (g) \\
\hline $\mathrm{S}_{\mathrm{A} 1}$ & $10: 0$ & 0.0750 & 0 & 5.0000 & 0.5000 \\
\hline $\mathrm{S}_{\mathrm{A} 2}$ & $8: 2$ & 0.0600 & 0.0150 & 5.0000 & 0.5000 \\
\hline $\mathrm{S}_{\mathrm{A} 3}$ & $6: 4$ & 0.0450 & 0.0300 & 5.0000 & 0.5000 \\
\hline $\mathrm{S}_{\mathrm{A} 4}$ & $5: 5$ & 0.0375 & 0.0375 & 5.0000 & 0.5000 \\
\hline $\mathrm{S}_{\mathrm{A} 5}$ & $4: 6$ & 0.0300 & 0.0450 & 5.0000 & 0.5000 \\
\hline $\mathrm{S}_{\mathrm{A} 6}$ & $2: 8$ & 0.0150 & 0.0600 & 5.0000 & 0.5000 \\
\hline $\mathrm{S}_{\mathrm{A} 7}$ & $0: 10$ & 0 & 0.0750 & 5.0000 & 0.5000 \\
\hline
\end{tabular}


Table II. Compositions of spinning solution B

\begin{tabular}{|c|c|c|c|c|c|c|}
\hline Solution B & PANI:PAN (wt.\%) & PANI (g) & CSA (g) & APS (g) & DMF (g) & $\operatorname{PAN}(g)$ \\
\hline $\mathrm{S}_{\mathrm{B} 1}$ & 15 & 0.1350 & 0.1684 & 0.3308 & 9.0000 & 0.9000 \\
\hline $\mathrm{S}_{\mathrm{B} 2}$ & 30 & 0.2700 & 0.3367 & 0.6616 & 9.0000 & 0.9000 \\
\hline $\mathrm{S}_{\mathrm{B} 3}$ & 50 & 0.4500 & 0.5620 & 1.1036 & 9.0000 & 0.9000 \\
\hline $\mathrm{S}_{\mathrm{B} 4}$ & 70 & 0.6300 & 0.7862 & 1.5439 & 9.0000 & 0.9000 \\
\hline
\end{tabular}

(a)

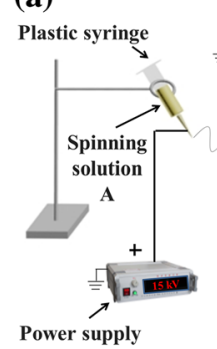

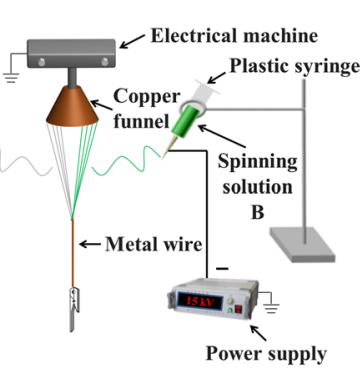
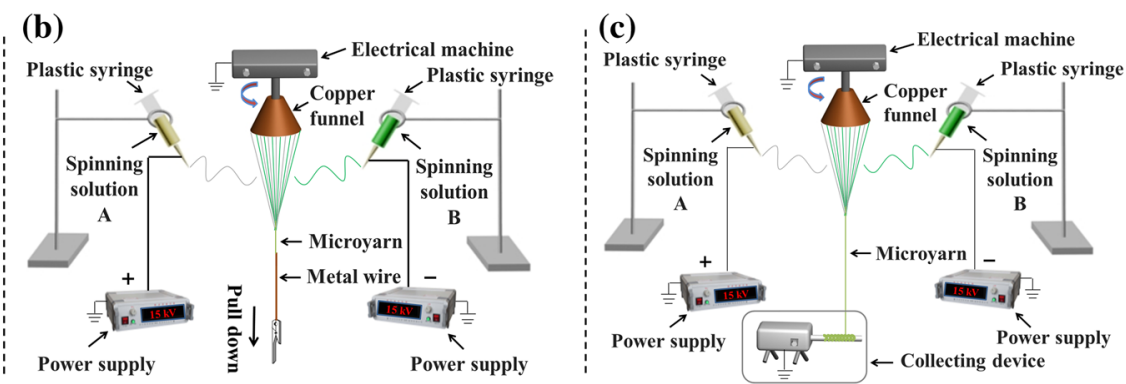

Fig. 1. Schematic diagram for the fabrication process of microyarns: (a) formation of ordered fiber bundles (b) formation of hollow-cone shaped nanofiber bundles and microyarns (c) collection of microyarns.

structure and the nanofibers in the yarns are closely packed together. By close observation with high magnification SEM, as indicated in Fig. 2c and g, the arrangement of the nanofibers in the microyarns is very regular, which widens the application fields of the nanofibers. The EDS spectra of heterostructured and homo-structured microyarns are displayed in Fig. $2 \mathrm{~b}$ and $\mathrm{f}$, which evidence the existence of $\mathrm{C}, \mathrm{N}, \mathrm{O}, \mathrm{Eu}, \mathrm{Tb}, \mathrm{Pt}$ and $\mathrm{S}$ elements. Element Pt results from the conductive film coated on the surface of the samples for SEM observation. Figure $2 d$ and $h$ show the histograms of the diameter distribution of nanofibers in the hetero-structured and homo-structured microyarns. The average diameters of the as-obtained hetero-structured microyarns and their inner nanofibers were $186 \mu \mathrm{m}$ and $508 \pm 11 \mathrm{~nm}$, respectively, and the mean diameters of the homo-structured microyarns and their interior nanofibers, respectively, were $166 \mu \mathrm{m}$ and $477 \pm 6 \mathrm{~nm}$.

\section{Luminescent Performance}

We first study the luminescent properties of hetero-structured microyarns with various proportions of RE complexes. The mass percentage of total content of RE complexes to PAN was set as $15 \%$ and the mass proportions of terbium to europium complexes respectively were 10:0 (S1), 8:2 (S2), 6:4 (S3), 5:5 (S4), 4:6 (S5), 2:8 (S6) and 0:10 (S7). In order to avoid the luminescent properties of the microyarns affected by the contents of PANI, the percent of PANI to PAN is fixed at $30 \%$. Figure $3 a$ and $b$ are the excitation spectra of hetero-structured microyarns when the monitored wavelengths were $544 \mathrm{~nm}$ and $615 \mathrm{~nm}$, respectively. As seen in Fig. 3a and $b$, there is a wide excitation peak between $200 \mathrm{~nm}$ and $375 \mathrm{~nm}$ and a maximum peak at $276 \mathrm{~nm}$, which is attributed to the $\pi \rightarrow \pi^{*}$ electron transition of the ligands. At the same time, by raising or decreasing the contents of $\mathrm{RE}$ complexes, the excitation peak intensity of the microyarns is also increased or weakened. Hence, from what has been discussed above, we can reasonably arrive at the conclusion that both the terbium and europium complexes can be simultaneously and efficiently excited by 276-nm ultraviolet (UV) light.

The emission spectra of hetero-structured microyarns (S1-S7) with various mass proportions of $\mathrm{Tb}(\mathrm{BA})_{3}$ phen to $\mathrm{Eu}(\mathrm{BA})_{3}$ phen are shown in Fig. 4a. It is evidently seen that there are four main emission peaks, respectively located at $490 \mathrm{~nm}$, $544 \mathrm{~nm}, 592 \mathrm{~nm}$ and $615 \mathrm{~nm}$, which are attributed to the ${ }^{5} \mathrm{D}_{4} \rightarrow{ }^{7} \mathrm{~F}_{6}$ and ${ }^{5} \mathrm{D}_{4} \rightarrow{ }^{7} \mathrm{~F}_{5}$ energy level transitions of $\mathrm{Tb}^{3+},{ }^{5} \mathrm{D}_{0} \rightarrow{ }^{7} \mathrm{~F}_{1}$ and ${ }^{5} \mathrm{D}_{0} \rightarrow{ }^{7} \mathrm{~F}_{2}$ energy level transitions of $\mathrm{Eu}^{3+}$. With addition of more $\mathrm{Eu}(\mathrm{BA})_{3}$ phen into microyarns, the emission peaks ascribed to $\mathrm{Eu}^{3+}$ ions show an upward tendency and those assigned to $\mathrm{Tb}^{3+}$ ions are decreased, and vice versa. To more distinctly highlight the above trends, the intensities of the characteristic emission peaks of hetero-structured microyarns are depicted in Fig. 4b. Hence, the luminescent intensity of the hetero-structured microyarns can be adjusted by modulating the proportion of $\mathrm{RE}$ complexes when the excitation light is $276 \mathrm{~nm}$.

Figure 5 shows the fluorescence decay curves of $\mathrm{Tb}^{3+}$ and $\mathrm{Eu}^{3+}$ ions in hetero-structured microyarns with various proportions of $\mathrm{Tb}(\mathrm{BA})_{3}$ phen to $\mathrm{Eu}(\mathrm{BA})_{3}$ phen complexes. These decay curves illustrate the decay lifetime and demonstrate the 

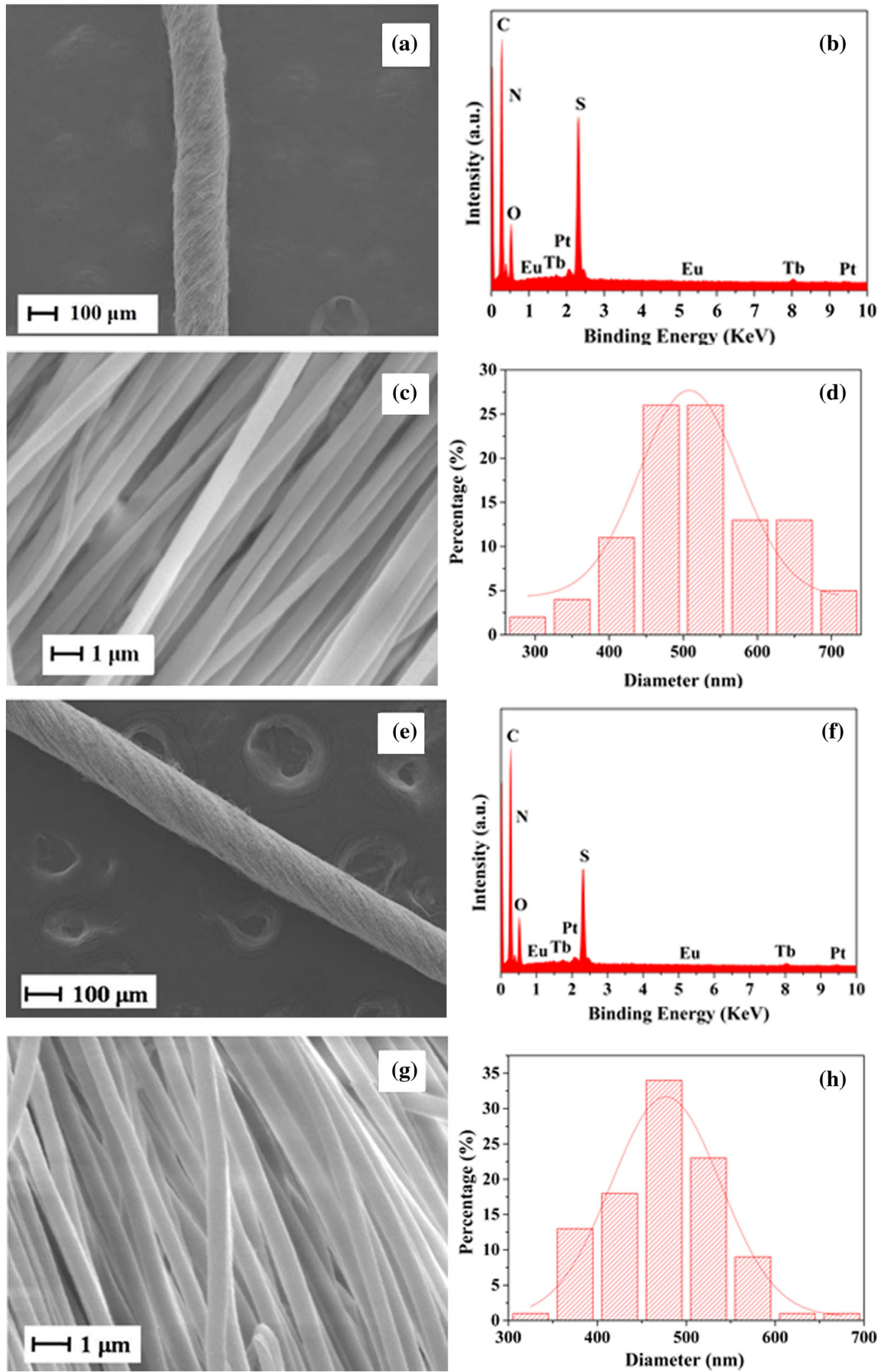

Fig. 2. SEM images at low (a, e) and high magnification (c, g), EDS spectra (b, f), the histograms of the diameter distribution (d, h) of the nanofibers in hetero-structured microyarns $(a, b, c, d)$ and homo-structured microyarns (e, f, g, h).

fluorescence kinetics of the hetero-structured microyarns. The microyarns are analyzed specifically at $544 \mathrm{~nm}$ and $615 \mathrm{~nm}$ when 276-nm UV light is used as the excitation wavelength. By fitting, it is found that the fluorescence lifetime of all samples presents a single exponential decay (Eq. 1): 

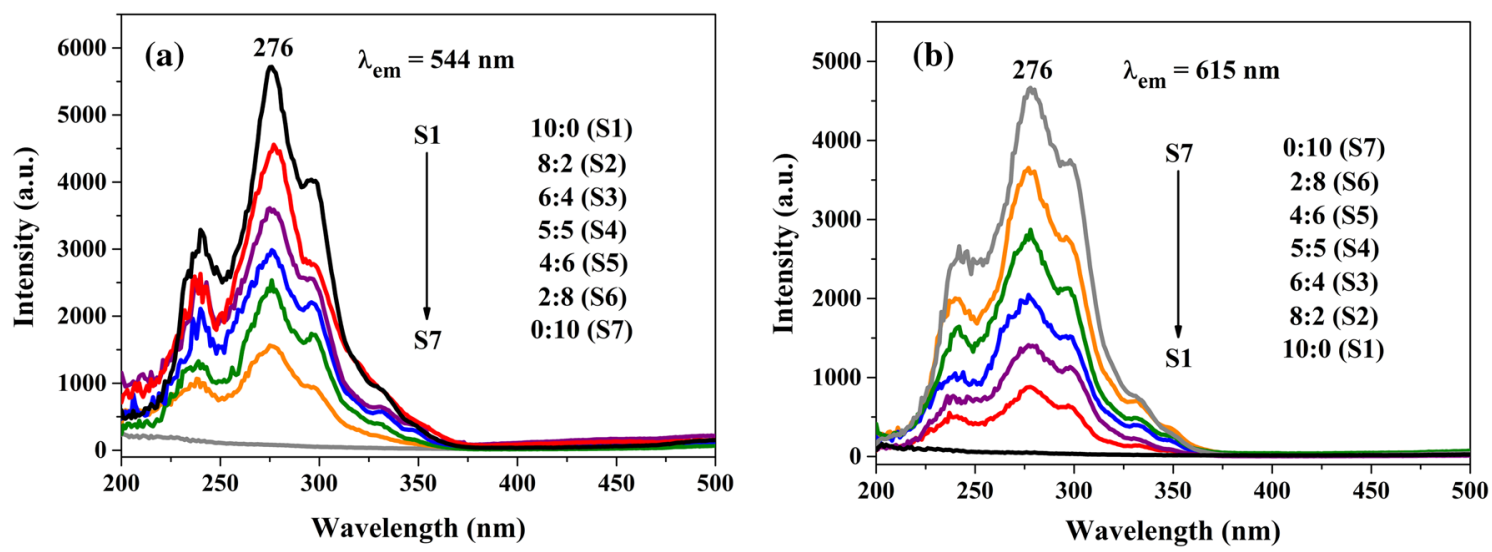

Fig. 3. Excitation spectra of hetero-structured microyarns with various mass proportions of $\mathrm{Tb}(\mathrm{BA})_{3}$ phen to $\mathrm{Eu}(\mathrm{BA})_{3}$ phen monitored at $544 \mathrm{~nm}$ (a) and $615 \mathrm{~nm}(\mathrm{~b})$.
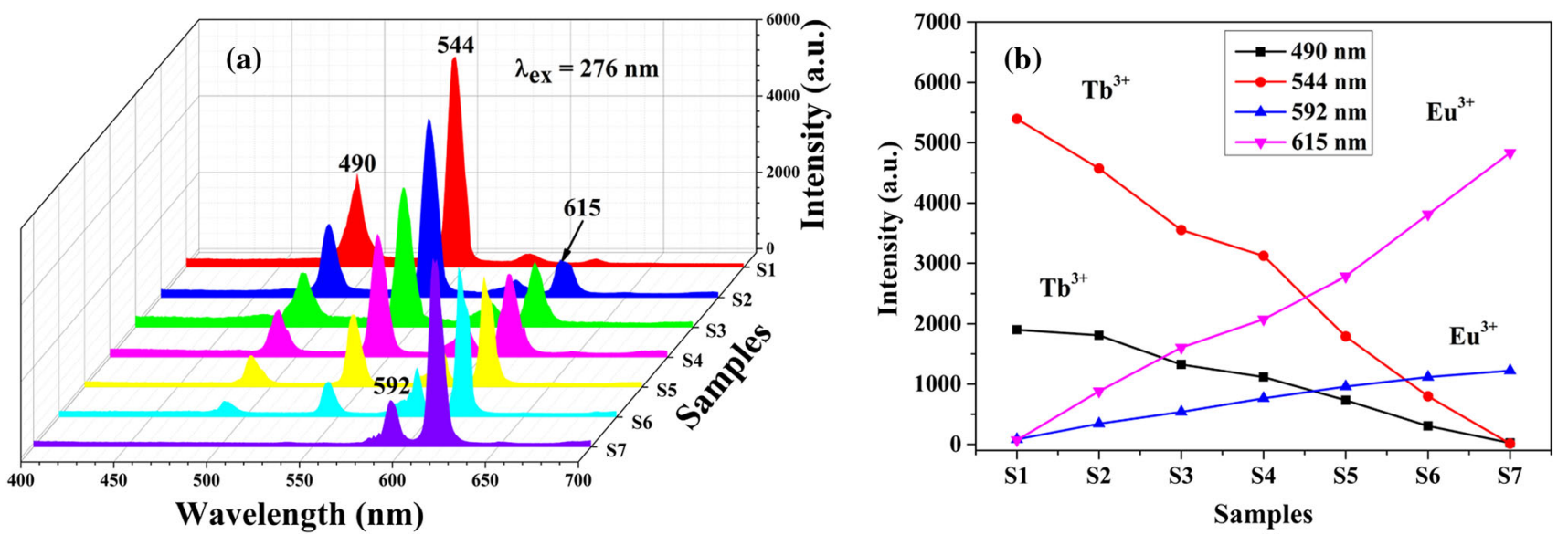

Fig. 4. Emission spectra of hetero-structured microyarns with various mass proportions of $\mathrm{Tb}(\mathrm{BA})_{3} \mathrm{phen}$ to $\mathrm{Eu}(\mathrm{BA})_{3}$ phen $(\mathrm{a})$ and the plots for intensities of the characteristic emission peaks of every sample (b).
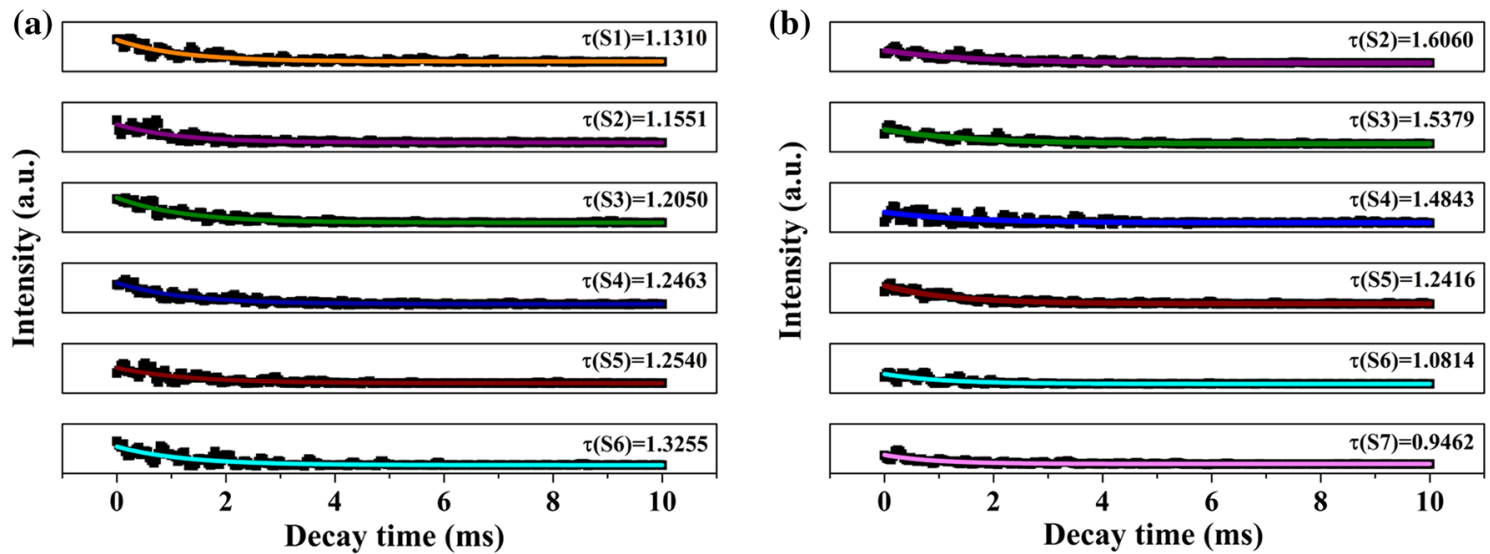

Fig. 5. Fluorescence decay dynamics of the (a) ${ }^{5} D_{4} \rightarrow{ }^{7} F_{5}$ transitions $\left(\lambda_{\text {em }}=544 \mathrm{~nm}\right)$ and (b) ${ }^{5} D_{0} \rightarrow{ }^{7} F_{2}$ transitions $\left(\lambda_{\text {em }}=615 \mathrm{~nm}\right)$ in the hetero-structured microyarns doped with various mass ratios of $\mathrm{Tb}(\mathrm{BA})_{3}$ phen to $\mathrm{Eu}(\mathrm{BA})_{3}$ phen complexes. 


$$
I_{t}=I_{0} \exp (-t / \tau)
$$

where $I_{t}$ and $I_{0}$ respectively are the intensity at time $t$ and $t=0, \tau$ is the decay lifetime. Average decay lifetime of $\mathrm{Tb}^{3+}$ and $\mathrm{Eu}^{3+}$ ions in the as-obtained samples are also displayed in Fig. 5. It is found that the lifetime of $\mathrm{Tb}^{3+}$ ions is shortened with adding more contents of $\mathrm{Tb}(\mathrm{BA})_{3}$ phen, as shown in Fig. 5a. Similarly, with the increase of $\mathrm{Eu}^{3+}$ ion contents, the fluorescence lifetime is also decreased, as illustrated in Fig. 5b. This may be explained as follows: by introducing more $\mathrm{Tb}(\mathrm{BA})_{3}$ phen complexes into microyarns, more aggregates of $\mathrm{Tb}(\mathrm{BA})_{3}$ phen are generated, and the exciton migration among $\mathrm{Tb}(\mathrm{BA})_{3}$ phen cut down the fluorescence lifetime of $\mathrm{Tb}^{3+}$ ions. The same is true for $\mathrm{Eu}(\mathrm{BA})_{3}$ phen.

In order to further understand the luminescent colors of the hetero-structured microyarns, the CIE chromaticity coordinates diagram of the microyarns were obtained by using CIE software, as displayed in Fig. 6, and the corresponding color coordinates are listed in Table III. As seen in Fig. 6, the color of light emitted from the samples under 276-nm UV illumination appears in the red area, yellow area and green region, which means that the luminescence color range of the samples from green, yellow to red can be tailored by adjusting the proportions of $\mathrm{Tb}^{3+}$ and $\mathrm{Eu}^{3+}$ ions.

We also investigated the luminescence properties of hetero-structured microyarns with different amounts of PANI (S4, S8-S10). The mass percentages of PANI were set to $15 \%$ (S8), $30 \%$ (S4), $50 \%$ (S9) and $70 \%$ (S10), while the proportion of $\mathrm{Tb}^{3+}$ to $\mathrm{Eu}^{3+}$ ions was fixed at 5:5. As shown in the left part of Fig. 7, one can see that the intensities of emission peaks decrease with the addition of PANI contents. Previous study reveals that PANI has strong absorption for light in the region of $400-800 \mathrm{~nm}^{64}$ Hence, PANI can absorb the emission light in the wavelengths of $490 \mathrm{~nm}, 544 \mathrm{~nm}, 593 \mathrm{~nm}$ and $615 \mathrm{~nm}$ and excitation light in the wavelength of $276 \mathrm{~nm}$ of the hetero-structured microyarns. Further, the more PANI added into the hetero-structured microyarns, the stronger the light absorption by PANI, and the deeper green the color of the samples. ${ }^{65}$ The CIE chromaticity coordinates for the microyarns with excitation at 276-nm UV light are illustrated in the right part of Fig. 7, and the corresponding color coordinates are summarized in Table IV. Under the condition of fixing the proportion of $\mathrm{Tb}^{3+}$ and $\mathrm{Eu}^{3+}$ ions and increasing PANI contents, the emission light color of the yarns slightly changes, but it is still yellow. The analysis results mean that the color of light emitted by the microyarns is little influenced by the change of PANI contents.

The excitation (a, b) and emission (c) spectra of hetero-structured microyarns (S4) and homo-structured microyarns (S14) are revealed in Fig. 8. The interesting finding is that hetero-structured microyarns possess excellent luminescent properties, but

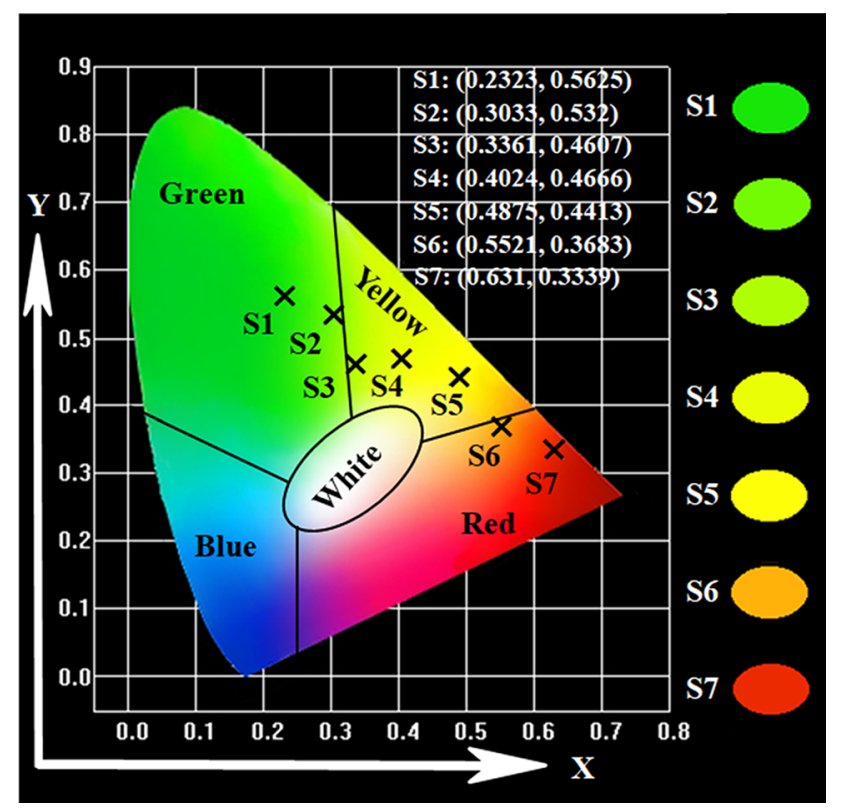

Fig. 6. CIE chromaticity coordinates diagram of the heterostructured microyarns and corresponding colors under 276-nm UV light excitation.

Table III. CIE chromaticity coordinates for heterostructured microyarns (S1-S7) excited by 276-nm UV light

\begin{tabular}{lcccc}
\hline Samples & & Concentration & & CIE coordinates $(\boldsymbol{x}, \boldsymbol{y})$ \\
\cline { 1 - 1 } S1 & & $100 \% \mathrm{~Tb}^{3+}, 0 \% \mathrm{Eu}^{3+}$ & & $(0.2323,0.5625)$ \\
S2 & & $80 \% \mathrm{~Tb}^{3+}, 20 \% \mathrm{Eu}^{3+}$ & & $(0.3033,0.532)$ \\
S3 & & $60 \% \mathrm{~Tb}^{3+}, 40 \% \mathrm{Eu}^{3+}$ & & $(0.3361,0.4607)$ \\
S4 & & $50 \% \mathrm{~Tb}^{3+}, 50 \% \mathrm{Eu}^{3+}$ & & $(0.4024,0.4666)$ \\
S5 & & $40 \% \mathrm{~Tb}^{3+}, 60 \% \mathrm{Eu}^{3+}$ & & $(0.4875,0.4413)$ \\
S6 & $20 \% \mathrm{~Tb}^{3+}, 80 \% \mathrm{Eu}^{3+}$ & & $(0.5521,0.3683)$ \\
S7 & $0 \% \mathrm{~Tb}^{3+}, 100 \% \mathrm{Eu}^{3+}$ & & $(0.631,0.3339)$ \\
\hline
\end{tabular}

the homo-structured microyarns show very weak intensity of excitation and emission peaks under the same compositions, contents, preparation methods and conditions. The luminescent intensity of heterostructured microyarns is significantly improved, which is about 33 times larger than that of homostructured microyarns. In order to explain the above phenomenon more obviously and intuitively, the schematic diagrams of the light in hetero-structured and homo-structured microyarns are demonstrated in Fig. 9, which displays the detailed internal structure of the microyarns. As manifested in Fig. 9a, hetero-structured microyarns are composed of two kinds of nanofibers which are green-colored PANI/PAN electrical nanofibers and white-colored luminescent $\left[\mathrm{Tb}(\mathrm{BA})_{3}\right.$ phen $+\mathrm{Eu}(\mathrm{BA})_{3}$ phen $] / \mathrm{PAN}$ nanofibers, respectively. RE complexes and PANI are distributed in different nanofibers, making the luminescence intensities of $\mathrm{Tb}^{3+}$ and $\mathrm{Eu}^{3+}$ ions almost unaffected by PANI. This peculiar structure greatly improves the overall luminescence of the 

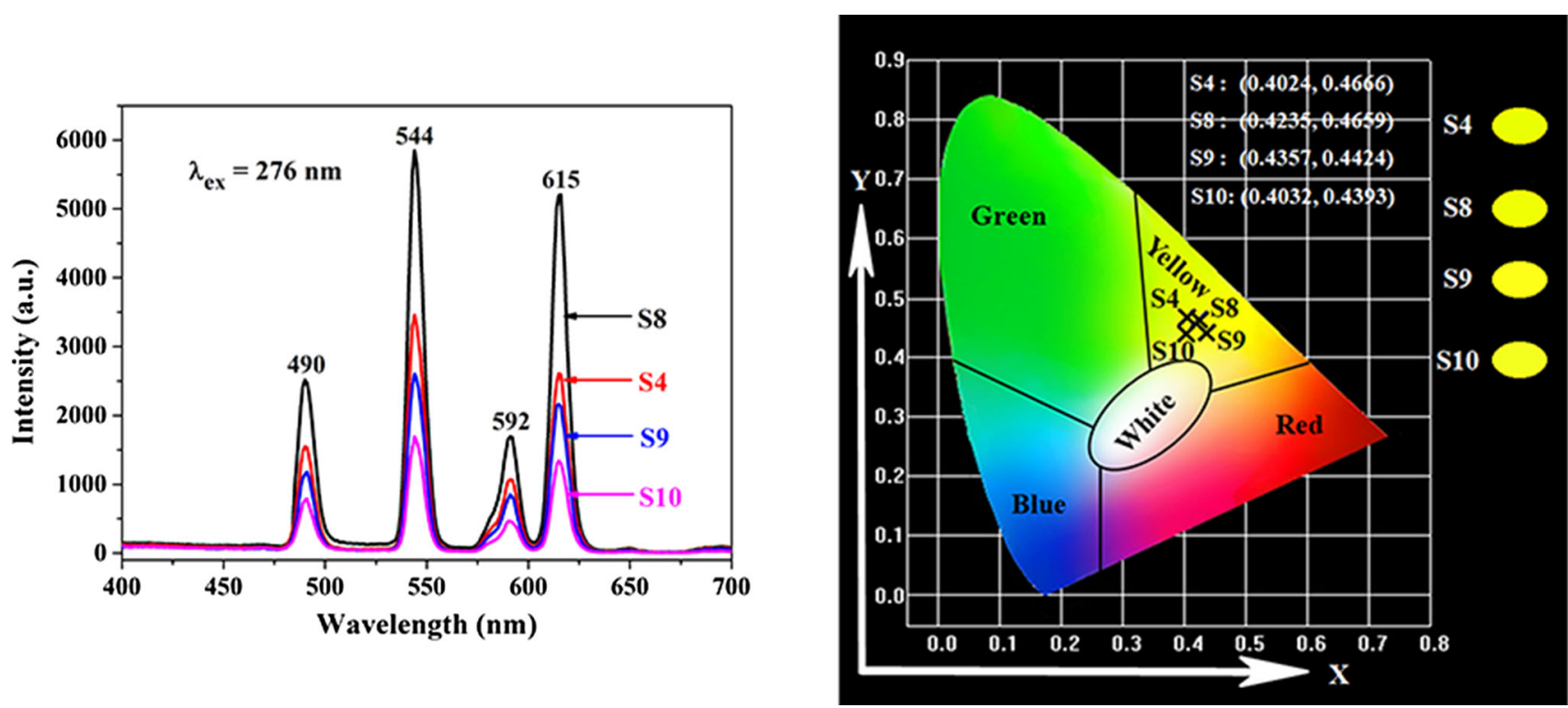

Fig. 7. Emission spectra (left) and CIE chromaticity coordinates diagram (right) of hetero-structured microyarns containing various mass percentages of PANI when the mass ratio of $\mathrm{Tb}(\mathrm{BA})_{3}$ phen to $\mathrm{Eu}(\mathrm{BA})_{3}$ phen was fixed at 5:5.

Table IV. CIE chromaticity coordinates for hetero-structured microyarns (S4, S8-S10) excited by 276-nm UV light

\begin{tabular}{lcc}
\hline Samples & PANI:PAN (\%) & CIE coordinates $(\boldsymbol{x}, \boldsymbol{y})$ \\
\cline { 3 - 3 } S4 & 30 & $(0.4024,0.4666)$ \\
S8 & 15 & $(0.4235,0.4659)$ \\
S9 & 50 & $(0.4357,0.4424)$ \\
S10 & 70 & $(0.4032,0.4393)$ \\
\hline
\end{tabular}
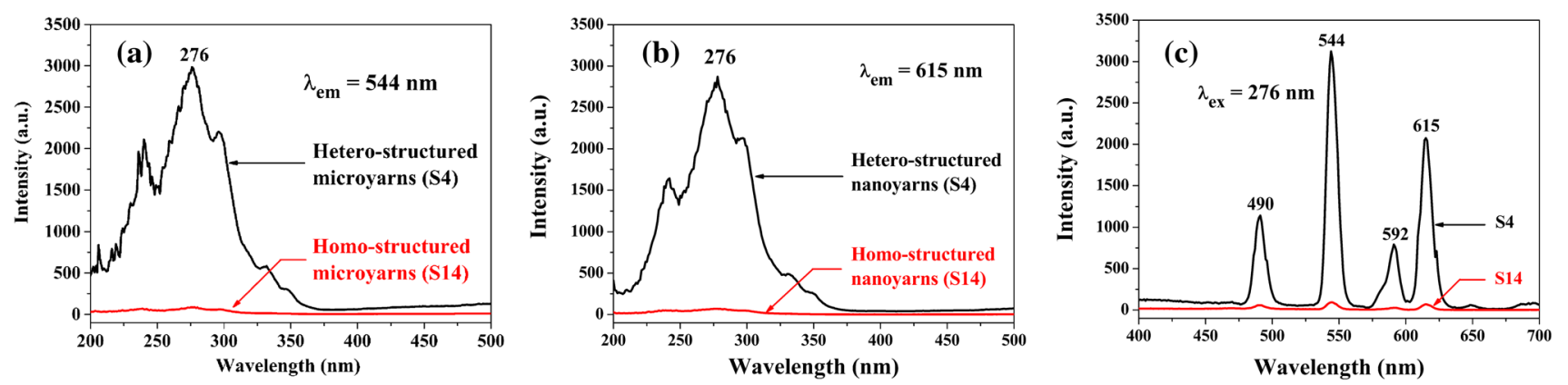

Fig. 8. Excitation spectra monitored at $544 \mathrm{~nm}$ (a), $615 \mathrm{~nm}$ (b) and emission spectra (c) of hetero-structured microyarns (S4) and homostructured microyarns (S14).

hetero-structured microyarns to a certain extent. As illustrated in Fig. 9b, homo-structured microyarns contain only one kind of nanofiber, namely the green-colored composite nanofibers. RE complexes and PANI are randomly distributed in every nanofiber in the homo-structured microyarns. Hence, the excitation light must pass through PANI to reach and excite the $\mathrm{Tb}(\mathrm{BA})_{3}$ phen and $\mathrm{Eu}(\mathrm{BA})_{3-}$ phen complexes. As this partial excitation light is absorbed by PANI in this process, the excitation light is weakened before approaching the RE complexes. Analogously, the emission light emitted by RE complexes also has to across the PANI and is absorbed by them. The result is that both the excitation light and the emission light are badly decreased. This explains why hetero-structured microyarns have superior luminescence properties. 


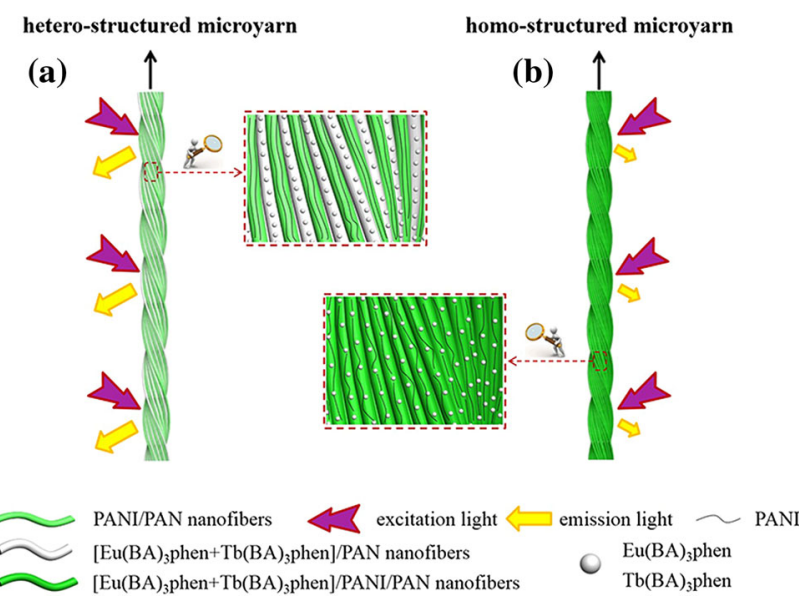

Fig. 9. Schematic diagrams of the exciting light and emitting light in the hetero-structured microyarns (a) and homo-structured microyarns (b).

Table V. Electrical conductivities of the heterostructured microyarns with various mass percentages of PANI and homo-structured microyarns

\begin{tabular}{|c|c|c|c|}
\hline \multirow[b]{2}{*}{ Samples } & \multirow[b]{2}{*}{$\begin{array}{c}\text { PANI:PAN } \\
\text { (wt.\%) }\end{array}$} & \multicolumn{2}{|c|}{ Conductivity $\left(\mathrm{S} \mathrm{cm}^{-1}\right)$} \\
\hline & & $\begin{array}{c}\text { Measurement } \\
\text { values }\end{array}$ & $\begin{array}{l}\text { Average } \\
\text { values }\end{array}$ \\
\hline S8 & 15 & $\begin{array}{l}2.76 \times 10^{-4} \\
2.51 \times 10^{-4} \\
2.46 \times 10^{-4}\end{array}$ & $2.58 \times 10^{-4}$ \\
\hline $\mathrm{S} 4$ & 30 & $\begin{array}{l}5.17 \times 10^{-4} \\
6.20 \times 10^{-4} \\
6.47 \times 10^{-4}\end{array}$ & $5.94 \times 10^{-4}$ \\
\hline S9 & 50 & $\begin{array}{l}1.10 \times 10^{-3} \\
9.72 \times 10^{-4} \\
1.20 \times 10^{-3}\end{array}$ & $1.09 \times 10^{-3}$ \\
\hline $\mathrm{S} 10$ & 70 & $\begin{array}{l}4.20 \times 10^{-3} \\
4.12 \times 10^{-3} \\
3.76 \times 10^{-3}\end{array}$ & $4.03 \times 10^{-3}$ \\
\hline S14 & 30 & $\begin{array}{l}5.99 \times 10^{-4} \\
4.61 \times 10^{-4} \\
5.13 \times 10^{-4}\end{array}$ & $5.24 \times 10^{-4}$ \\
\hline
\end{tabular}

\section{Electrical Properties}

The electrical conductivities of homo-structured microyarns and hetero-structured microyarns with different percentages of PANI were measured by a four-probe tester, and the test results are shown in Table V. It is well-known that the charge transport ability provided by connecting conductive network plays a very important role in the conductivity of PANI. ${ }^{66}$ As seen in Table V, the average conductivity values of the hetero-structured microyarns increase gradually from $2.58 \times 10^{-4} \mathrm{~S} \mathrm{~cm}^{-1}$ to $4.03 \times 10^{-3} \mathrm{~S} \mathrm{~cm}^{-1}$, while the percentages of PANI to PAN range from $15 \%$ to $70 \%$. The electrical
Table VI. Electrical conductivities of the heterostructured microyarns under different rotating speeds of copper funnel

\begin{tabular}{|c|c|c|c|}
\hline \multirow[b]{2}{*}{ Samples } & \multirow{2}{*}{$\begin{array}{c}\text { Rotating } \\
\text { speeds of } \\
\text { copper fun- } \\
\text { nel }\left(r \text { min }^{-1}\right)\end{array}$} & \multicolumn{2}{|c|}{ Conductivity $\left(\mathrm{S} \mathrm{cm}^{-1}\right)$} \\
\hline & & $\begin{array}{l}\text { Measurement } \\
\text { values }\end{array}$ & $\begin{array}{c}\text { Average } \\
\text { values }\end{array}$ \\
\hline S11 & 10 & $\begin{array}{l}4.95 \times 10^{-4} \\
5.13 \times 10^{-4} \\
5.02 \times 10^{-4}\end{array}$ & $5.03 \times 10^{-4}$ \\
\hline $\mathrm{S} 12$ & 40 & $\begin{array}{l}5.33 \times 10^{-4} \\
5.81 \times 10^{-4} \\
5.12 \times 10^{-4}\end{array}$ & $5.42 \times 10^{-4}$ \\
\hline $\mathrm{S} 13$ & 70 & $\begin{array}{l}6.25 \times 10^{-4} \\
5.62 \times 10^{-4} \\
5.16 \times 10^{-4}\end{array}$ & $5.67 \times 10^{-3}$ \\
\hline $\mathrm{S} 4$ & 100 & $\begin{array}{l}5.17 \times 10^{-4} \\
6.20 \times 10^{-4} \\
6.47 \times 10^{-4}\end{array}$ & $5.95 \times 10^{-4}$ \\
\hline
\end{tabular}

conductivity of the hetero-structured microyarns can be adjusted by modulating the contents of PANI. This result can be interpreted by the fact that with addition of more PANI into hetero-structured microyarns, the continuity of the conductive network of PANI is improved. It is also found from the Table $\mathrm{V}$ that the electrical conductivity of the hetero-structured microyarns is slightly stronger than that of the homo-structured microyarns. This is due to the presence of the insulating $\mathrm{RE}$ complexes distributed in all of the nanofibers in homostructured microyarns, which impedes the generation of continuous conductive network to some degree.

We also investigated the influence of a copper funnel with different rotational speeds on the electrical conductivity of the hetero-structured microyarns (S11-S13, S4), and the test results are summarized in Table VI. The electrical conductivity of hetero-structured microyarns gradually increases with the increase of the funnel rotation speeds. this can be explained as follow: the faster the rotation speeds of the copper funnel, the greater the twist angle of the microyarns, and the more compact the arrangement of the nanofibers in the yarns, ${ }^{67}$ which improves the conductivity of the hetero-structured microyarns.

\section{CONCLUSIONS}

In summary, a hetero-structured microyarn with electrical conductivity and color-tuned luminescence was successfully fabricated by a conjugate electrospinning technique. The hetero-structured microyarns have distinctly twisted structure and the fibers in the microyarns display high orientation with close alignment. The hetero-structured microyarns have enhanced luminescent properties owing 
to the fact that hetero-structured microyarns are composed of two kinds of nanofibers with different properties to achieve the effective separation of light-colored RE complexes from dark-colored PANI. In addition, the electrical conductivity and emitting color of the hetero-structured microyarns can be modulated via changing the contents of PANI and the proportion of $\mathrm{RE}$ complexes, respectively. The design philosophy and construction technique described here could be extended for fabricating other multifunctional microyarns, with possible applications such as in molecular electronics and in full-color displays.

\section{ACKNOWLEDGMENTS}

This work was financially supported by National Natural Science Foundation of China (51573023, 51803012, 50972020), Natural Science Foundation of Jilin Province (20170101101JC, 20180520011JH), Industrial Technology Research and Development Project of Jilin Province Development and Reform Commission (2017C052-4), Science and Technology Research Planning Project of the Education Department of Jilin Province during the 13th fiveyear plan period (JJKH20170608KJ, JJKH20181122KJ), and Innovative Foundation (XJJLG-2017-04) and Youth Foundation (XQNJJ2016-01, XQNJJ-2017-17) of Changchun University of Science and Technology.

\section{CONFLICT OF INTEREST}

The authors declare that they have no conflict of interest.

\section{REFERENCES}

1. J. Chen and Z.L. Wang, Joule 1, 480 (2017).

2. N.N. Zhang, J. Chen, Y. Huang, W.W. Guo, J. Yang, J. Du, X. Fan, and C.Y. Tao, Adv. Mater. 28, 263 (2016).

3. J. Chen, Y. Huang, N.N. Zhang, H.Y. Zou, R.Y. Liu, C.Y. Tao, X. Fan, and Z.L. Wang, Nat. Energy 1, 16138 (2016).

4. N.N. Zhang, C.Y. Tao, X. Fan, and J. Chen, J. Mater. Res. 32, 1628 (2017).

5. Y.C. Peng, J. Chen, A.Y. Song, P.B. Catrysse, P.C. Hsu, L.L. Cai, B.F. Liu, Y.Y. Zhu, G.M. Zhou, D.S. Wu, H.R. Lee, S.H. Fan, and Y. Cui, Nat. Sustain. 1, 105 (2018).

6. Z.M. Lin, J. Yang, X.S. Li, Y.F. Wu, W. Wei, J. Liu, J. Chen, and J. Yang, Adv. Funct. Mater. 28, 1704112 (2018).

7. L.L. Cai, A.Y. Song, P.I. Wu, P.C. Hsu, Y.C. Peng, J. Chen, C. Liu, P.B. Catrysse, Y.Y. Liu, A.K. Yang, C.X. Zhou, C.Y. Zhou, S.H. Fan, and Y. Cui, Nat. Commun. 8, 496 (2017).

8. Z.M. Lin, J. Chen, and J. Yang, J. Nanomater. 2016, 56516613 (2016).

9. Z.L. Li, J. Chen, J.J. Zhou, L. Zheng, K.C. Pradel, X. Fan, H.Y. Guo, Z. Wen, M.H. Yeh, C.W. Yu, and Z.L. Wang, Nano Energy 22, 548 (2016).

10. R.Y. Liu, X. Kuang, J.N. Deng, Y.C. Wang, A.C. Wang, W.B. Ding, Y.C. Lai, J. Chen, P.H. Wang, Z.Q. Lin, H.J. Qi, B.Q. Sun, and Z.L. Wang, Adv. Mater. 30, 1705195 (2018).

11. G. Zhu, J. Chen, T.J. Zhang, Q.S. Jing, and Z.L. Wang, Nat. Commun. 5, 3426 (2014).

12. J. Chen, G. Zhu, W.Q. Yang, Q.S. Jing, P. Bai, Y. Yang, and T.C. Hou, Adv. Mater. 25, 6094 (2013).

13. J. Chen, J. Yang, Z.L. Li, X. Fan, Y.L. Zi, Q.S. Jing, H.Y. Guo, Z. Wen, K.C. Pradel, S.M. Niu, and Z.L. Wang, ACS Nano 9, 3324 (2015).
14. Z.L. Li, J. Chen, H.Y. Guo, X. Fan, Z. Wen, M.H. Yeh, C.W Yu, X. Cao, and Z.L. Wang, Adv. Mater. 28, 2983 (2016).

15. Y. Wu, Q.S. Jing, J. Chen, P. Bai, J.J. Bai, G. Zhu, Y.J. Su, and Z.L. Wang, Adv. Funct. Mater. 25, 2166 (2015).

16. J. Chen, J. Yang, H.Y. Guo, Z.L. Li, L. Zheng, Y.J. Su, Z. Wen, X. Fan, and Z.L. Wang, ACS Nano 9, 12334 (2015).

17. Z.M. Lin, J. Chen, X.S. Li, Z.H. Zhou, K.Y. Meng, W. Wei, J. Yang, and Z.L. Wang, ACS Nano 11, 8830 (2017).

18. S.Y. Kuang, J. Chen, X.B. Cheng, G. Zhu, and Z.L. Wang, Nano Energy 17, 10 (2015).

19. J. Chen, G. Zhu, J. Yang, Q.S. Jing, P. Bai, W.Q. Yang, X.W. Qi, Y.J. Su, and Z.L. Wang, ACS Nano 9, 105 (2015).

20. L. Zheng, G. Cheng, J. Chen, L. Lin, J. Wang, Y.S. Liu, H.X. Li, and Z.L. Wang, Adv. Energy Mater. 5, 1501152 (2015).

21. Y. Lu and S. Ozcan, Nano Today 10, 417 (2015).

22. C.M. Park, K.H. Chu, J. Heo, N. Her, M. Jang, A. Son, and Y. Yoon, J. Hazard. Mater. 309, 133 (2016).

23. K. Chen, L. Ma, J.H. Wang, Z.Q. Cheng, D.J. Yang, Y.Y. Li, S.J. Ding, L. Zhou, and Q.Q. Wang, RSC Adv. 7, 26097 (2017).

24. L. Ma, K. Chen, F. Nan, J.H. Wang, D.J. Yang, L. Zhou, and Q.Q. Wang, Adv. Funct. Mater. 26, 6076 (2016).

25. J. Tian, Q.L. Ma, X.T. Dong, W.S. Yu, M. Yang, Y. Yang, J.X. Wang, and G.X. Liu, RSC Adv. 6, 36180 (2016).

26. K. Lun, Q.L. Ma, X.T. Dong, W.S. Yu, J.X. Wang, and G.X. Liu, J. Mater. Sci. Mater. Electron. 25, 5395 (2014).

27. M. Chen, J.H. Wang, Z.J. Luo, Z.Q. Cheng, Y.F. Zhang, X.F. Yu, L. Zhou, and Q.Q. Wang, RSC Adv. 6, 9612 (2016).

28. G.H. Du, P. Liu, W.W. Guo, Y.B. Han, J. Zhang, Z.W. Ma, J.B. Han, Z.L. Liu, and K.L. Yao, J. Mater. Chem. C 1, 7608 (2013).

29. F. Wang and X.G. Liu, Acc. Chem. Res. 47, 1378 (2014).

30. Y. Tian, Y. Wei, Y. Zhao, Z.W. Quan, G.G. Li, and J. Lin, J. Mater. Chem. C 4, 1281 (2016).

31. J. Jang, J.H. Oh, and G.D. Stucky, Angew. Chem. Int. Ed. 41, 4016 (2002).

32. P.H. Liu, S.H. Wu, Y. Zhang, H.G. Zhang, and X.H. Qin, Nanomaterials 6, 121 (2016).

33. A. Jasim, M.W. Ullah, Z.J. Shi, X. Lin, and G. Yang, Carbohydr. Polym. 163, 62 (2017).

34. P.P. Yu, X. Zhao, Y.Z. Li, and Q.H. Zhang, Appl. Surf. Sci. 393, 37 (2017).

35. P. Bandyopadhyay, T. Kuila, J. Balamurugan, T.T. Nguyen, N.H. Kim, and J.H. Lee, Chem. Eng. J. 308, 1174 (2017).

36. L. Kumar, I. Rawal, A. Kaur, and S. Annapoorni, Sens. Actuator B 240, 408 (2017).

37. Y.W. Liu, Q.L. Ma, M. Yang, X.T. Dong, Y. Yang, J.X. Wang, W.S. Yu, and G.X. Liu, Chem. Eng. J. 284, 831 (2016).

38. D. Li, Q.L. Ma, X. Xi, X.T. Dong, W.S. Yu, J.X. Wang, and G.X. Liu, Chem. Eng. J. 309, 230 (2017).

39. X.B. Li, Q.L. Ma, J. Tian, X. Xi, D. Li, X.T. Dong, W.S. Yu, X.L. Wang, J.X. Wang, and G.X. Liu, Nanoscale 9, 18918 (2017).

40. N. Lv, J.L. Zhang, G.M. Li, X. Wang, and J.Z. Ni, J. Phys. Chem. C 121, 11926 (2017).

41. H.Y. Wang, Y. Wang, Y. Yang, X. Li, and C. Wang, Mater. Res. Bull. 44, 408 (2009).

42. N. Lv, Z.G. Wang, W.Z. Bi, G.M. Li, J.L. Zhang, and J.Z. Ni, J. Mater. Chem. B 4, 4402 (2016).

43. N. Lu, C.L. Shao, X.H. Li, F.J. Miao, K.X. Wang, and Y.C. Liu, Appl. Surf. Sci. 391, 668 (2017).

44. S. Thenmozhi, N. Dharmaraj, K. Kadirvelu, and H.Y. Kim, Mater. Sci. Eng. B 217, 36 (2017).

45. Z. Aytac, Z.I. Yildiz, F.K. Ayaci-Senirmak, T. Tekinay, and T. Uyar, Food Chem. 231, 192 (2017).

46. J.J. Xue, J.W. Xie, W.Y. Liu, and Y.N. Xia, Acc. Chem. Res. 50, 1976 (2017).

47. S.H. Wu, Y. Wang, P.N. Streubel, and B. Duan, Acta Biomater. 62, 102 (2017).

48. L. Tian, T. Yan, and Z.J. Pan, J. Mater. Sci. 50, 7137 (2015)

49. U. Ali, H. Niu, A. Abbas, H. Shao, and T. Lin, RSC Adv. 6, 30564 (2016).

50. C. Yao, X.S. Li, K.G. Neoh, Z.L. Shi, and E.T. Kang, Appl. Surf. Sci. 255, 3854 (2009). 
51. X.Y. Zheng, W. Wang, S. Liu, J.L. Wu, F.F. Li, L. Cao, X.D. Liu, X.M. Mo, and C.Y. Fan, Mater. Sci. Eng. C 58, 1071 (2016).

52. X.L. Ma, L.Y. Zhang, J. Tan, Y.X. Qin, and H.B. Chen, J. Appl. Polym. Sci. 134, 44820 (2017).

53. X.R. Li, M.Y. Li, J. Sun, Y. Zhuang, J.J. Shi, D.W. Guan, Y.Y. Chen, and J.W. Dai, Small 122, 5009 (2016).

54. F. Mehrpouya, J. Foroughi, S. Naficy, J. Razal, and M. Naebe, Nanomaterials 7, 293 (2017).

55. L.B. Fan, Q.L. Ma, J. Tian, D. Li, X. Xi, X.T. Dong, W.S. Yu, J.X. Wang, and G.X. Liu, J. Mater. Sci. 53, 2290 (2018).

56. D.W. Li, X. Pan, B.B. Sun, T. Wu, W.M. Chen, C. Huang, Q.F. Ke, H.A. Ei-Hamshary, S.S. Al-Deyab, and X.M. Mo, J. Mater. Chem. B 3, 8823 (2015).

57. S.H. Wu, P.H. Liu, Y. Zhang, H.G. Zhang, and X.H. Qin, Sens. Actuator B 252, 697 (2017).

58. S.K. Nataraj, K.S. Yang, and T.M. Aminabhavi, Prog. Polym. Sci. 37, 487 (2012).
59. F.J. Miao, C.L. Shao, X.H. Li, N. Lu, K.X. Wang, X. Zhang, and Y.C. Liu, Electrochim. Acta 176, 293 (2015).

60. R. Zhao, X. Li, B.L. Sun, H. Ji, and C. Wang, J. Colloid Interface Sci. 487, 297 (2017).

61. Q. Niu, J. Guo, B. Chen, J. Nie, X. Guo, and G. Ma, Carbon 114,250 (2017).

62. Q.L. Ma, J.X. Wang, X.T. Dong, W.S. Yu, and G.X. Liu, Chem. Eng. J. 222, 16 (2013).

63. Q.L. Ma, J.X. Wang, X.T. Dong, W.S. Yu, G.X. Liu, and J. $\mathrm{Xu}$, J. Mater. Chem. 22, 14438 (2012).

64. H. Shao, Q.L. Ma, X.T. Dong, W.S. Yu, M. Yang, Y. Yang, J.X. Wang, and G.X. Liu, Sci. Rep. 5, 14052 (2015).

65. L.B. Fan, Q.L. Ma, J. Tian, D. Li, X. Xi, X.T. Dong, W.S. Yu, J.X. Wang, and G.X. Liu, RSC Adv. 7, 48702 (2017).

66. Z.J. Wang, Q.L. Ma, X.T. Dong, D. Li, X. Xi, W.S. Yu, J.X. Wang, and G.X. Liu, ACS Appl. Mater. Interfaces 8, 26226 (2016).

67. J.X. He, K. Qi, Y.M. Zhou, and S.Z. Cui, J. Appl. Polym. Sci. 131, 631 (2014). 